\title{
Multi-objective optimization of CNC turning parameters using genetic algorithm and perfor- mance evaluation of nanocomposite coated carbide inserts
}

\author{
M. R. Pratheesh Kumar ${ }^{a^{*}}$, K. Saravanakumar ${ }^{a}$, S. Balakrishnan ${ }^{b}$ and R. Saravanan ${ }^{b}$
}

${ }^{a}$ Assistant Professor, Department of Production Engineering, PSG College of Technology, Coimbatore -641004, India ${ }^{b}$ Under Graduate Student, Department of Production Engineering, PSG College of Technology, Coimbatore -641004, India C H R O N I C L E

\section{Article history:}

Received: June 2, 2018

Received in revised format: June

19, 2018

Accepted: September 15, 2018

Available online:

September 15, 2018

Keywords:

Multi-objective optimization

Genetic algorithm

Inconel 600

ANOVA

Coated carbide insert \begin{abstract}
A B S T R A C T
Inconel 600 is a super alloy known for its properties like low thermal conductivity and work hardening. The work hardening property of this alloy makes it harder and harder during successive passes of the tool during machining. Therefore, machining of this type of material demands innovation in tool material, selection of proper combination of parameters and their levels for economical machining. Coated carbide tool inserts are most widely used for machining Inconel alloys. These inserts are coated with special materials by PVD or CVD technique to reduce flank wear, improve surface finish of machined components and increase the material removal rate (MRR). In this work carbide insert coated with nanocomposite coatings like AlTiN and TiAlSiN commercially known as Hyperlox and $\mathrm{HSN}^{2}$ were used and their performance during machining of Inconel 600 was studied. As improper selection of process parameter influences on the quality of products and productivity, it is important to identify the optimum combination of input process parameters. Most of the time the influence of the input process parameters on the output parameters like MRR, surface roughness and flank wear is studied independently. Information obtained through single objective optimization may not be sufficient because industries desire to optimize all the output parameters, simultaneously. Multi-objective optimization is the only solution to satisfy the requirements of industries and genetic algorithm based multi-objective optimization is adopted in this work in order to get the optimum combination of input process parameters to obtain maximum material removal rate, minimum surface roughness and minimum flank wear simultaneously.
\end{abstract}

(C) 2018 by the authors; licensee Growing Science, Canada.

\section{Introduction}

Inconel 600 is a nickel-based super alloy which is most widely used in applications where high strength and resistance to high temperature are required. It is a solution strengthened nickel based austenitic alloy (Zhang et al., 2014). The versatility of this alloy has led to its use in aerospace industries for making jet engines and aircraft turbines due to high yield strength, corrosion resistance and excellent fatigue resistance. The other applications of Inconel alloys include manufacturing of internal combustion engine parts, components of space vehicles, heat exchangers and parts used in petrochemical industries (Yadav et al., 2015). The presence of nickel in the alloy gives it corrosion resistance against most of the organic and inorganic chemicals used in the working environment (Del Prete et al., 2013). Machining of such

* Corresponding author. Tel: (+91)-9786417582

E-mail address: mrpratheesh@gmail.com (M. R. Pratheesh Kumar) 
novel materials can be done efficiently with tools which possess special characteristics. Coating carbide tool inserts with harder chemicals like AlTiN and TiAlSiN by Physical Vapour Deposition (PVD) or Chemical Vapour Deposition (CVD) technique will give the tool its strength and hardness. Therefore, they are being widely used for machining of aerospace alloys like Inconel 600. Conventional experimental design of combination of input parameters to conduct experiments has many complexities. The number of experiments to be conducted for the selected number of parameters will have an exponential relation. Taguchi's design eliminates the need for unnecessary experiments. It is also well known for its robustness (Ross, 2015).

The response or output parameters of machining like material removal rate (MRR), surface roughness and flank wear are a few important characteristics to be studied while machining a material. Surface roughness plays important role in improving corrosion resistance, fatigue strength, precision assembly of parts and tribological properties, whereas flank wear rate influences the tool life, surface finish, MRR and dimensional accuracy of machined components. Therefore, surface roughness, flank wear and MRR are taken as the parameters of interest in the study. Improper selection of machining parameters and their levels cause premature wear of cutting tools and also greatly affects the surface quality of the work material and MRR. In order to obtain the desired level of output parameters and to balance between the cost and quality of manufacturing the best combination of input parameters need to be identified. Artificial intelligence techniques like Genetic Algorithm (GA), Artificial Neural Network (ANN), Fuzzy Logic (FL) and Particle Swarm Optimization (PSO) are used to obtain the proper combination of input parameters (Sardinas et al., 2006). Genetic algorithm is a most widely used Artificial Intelligence technique for optimization. It has several advantages, including faster convergence rate to near global optima, and the ability to improve global optimum because of its specialized operators like crossover and mutation. Rather than selecting an individual in a close neighbourhood and getting trapped in local optima, these operators select random individuals (Pham \& Karaboga, 2009). The literature review reveals that most of the studies conducted on this material, were towards optimization of a single objective (Das et al., 2015). But, industry demands innovation in manufacturing processes and procedure where importance is distributed amongst various conflicting objectives like surface roughness, tool wear and material removal rate. Solving of multiple single objective problems of a process into a multi-objective problem was accomplished by Samanta and Chakraborty (2011). With this background multi-objective optimization of machining parameters to achieve minimum surface roughness, minimum flank wear of tool and maximum MRR is performed in this work.

\section{Experimental procedure}

\subsection{Material and Methods}

The material used for experimentation was Inconel 600 rods of diameter $50 \mathrm{~mm}$ and length $200 \mathrm{~mm}$. The experiments were carried out in Galaxy Midas-6 CNC turning centre. Carbide tool inserts coated with AlTiN supernitride of nanocomposite structure called Hyperlox ${ }^{\circledR}$ and TiAlSiN with 3-layer nanocomposite structure called $\mathrm{HSN}^{2 \circledR}$ with maximum application temperature of $1100^{\circ} \mathrm{C}$ were used for turning the work material. All the four cutting edges of each insert were used for machining. No coolant was used while machining the work material as it may neutralise the influence of coating materials on the response parameters like surface roughness $\left(\mathrm{R}_{\mathrm{a}}\right)$, flank wear $\left(\mathrm{V}_{\mathrm{B}}\right)$ and material removal rate (MRR). Surface roughness of the machined work material was measured using Mitutoyo SJ-210 surface roughness tester. The cut off length used for the measurement of surface roughness was $0.8 \mathrm{~mm}$. Flank wear of the tool was measured using Mitutoyo Tool maker's microscope with camera setup. The image of the tool insert was taken before and after each experimental trial in order to measure the tool wear by image processing technique using ImageJ software. Typical image of the tool insert obtained before and after each experiment is shown in Fig. 1. The MRR obtained for each combination of process parameters during experimentation was calculated with the help of the standard formula given in Eq. (1) and therefore the MRR remained the same for the two types of tool inserts (Sardinas et al., 2006).

$$
M R R=v_{s} \times f \times d,
$$


where, $v_{s}$ is the peripheral velocity of the spindle in $\mathrm{mm} / \mathrm{min}, f$ is the tool feed rate in $\mathrm{mm} / \mathrm{rev}$ and $d$ is the depth of cut in $\mathrm{mm}$.

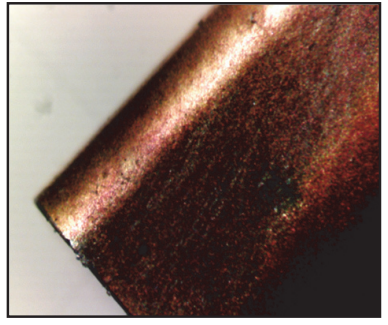

(a)

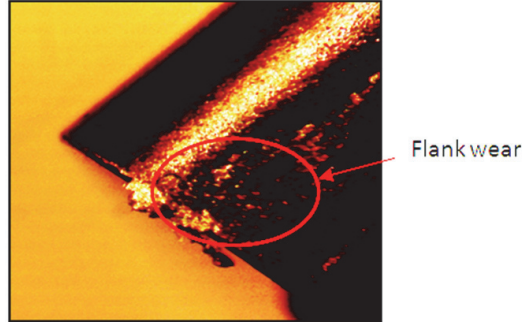

(b)

Fig.1. Tool insert (a) before machining and (b) after machining

\subsection{Experimental Design}

Three input process parameters which were proved to have a direct relationship with the output response parameters were chosen in this study based on literature review.

Table 1

Input parameters and their levels

\begin{tabular}{cccccc}
\hline \multirow{2}{*}{ Factors } & \multirow{2}{*}{ Unit } & Symbols & \multicolumn{3}{c}{ Levels } \\
\cline { 4 - 6 } & & & 1 & 2 & 3 \\
\hline Spindle speed & $\mathrm{rpm}$ & $v$ & 1500 & 2000 & 2500 \\
Depth of cut & $\mathrm{mm}$ & $d$ & 0.25 & 0.5 & 0.75 \\
Tool feed rate & $\mathrm{mm} / \mathrm{rev}$ & $f$ & 0.1 & 0.15 & 0.2 \\
\hline
\end{tabular}

Table 2

The $\mathrm{L}_{27}$ orthogonal array of input parameters and the output parameters obtained through experimentation

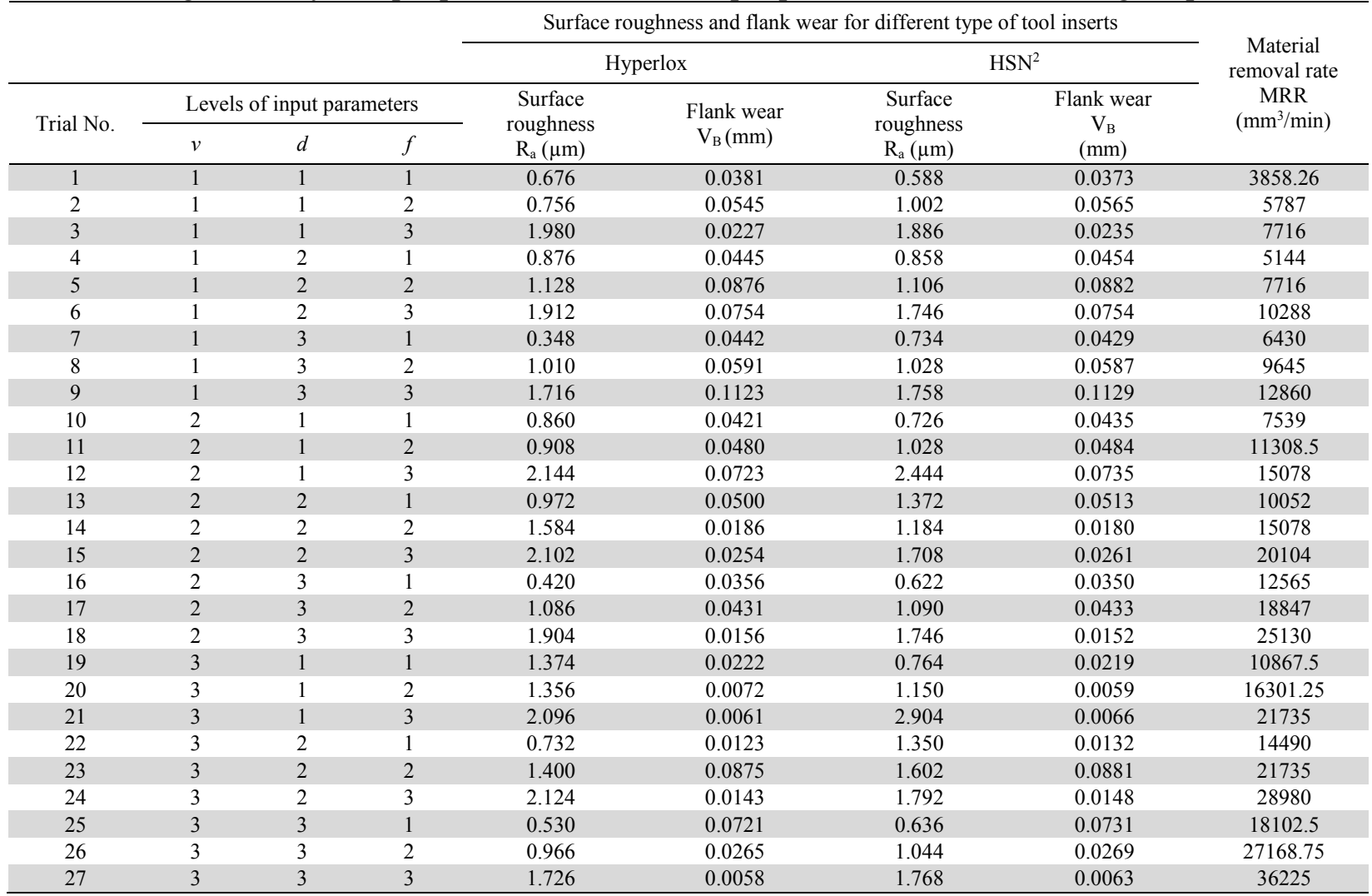


They are spindle speed, tool feed rate and depth of cut. The combination of input process parameters for conducting the experiments were formulated using Taguchi's orthogonal array to eliminate the conventional full factorial design (Wu \& Hamada, 2011) of experiments. The three factors and three levels of each of these parameters chosen are shown in Table 1 which is based on the capability of the machine and the cutting tool. In order to bring out the relationship between the input and response parameters, Taguchi's $\mathrm{L}_{27}$ orthogonal array was used due to its higher resolution factor when compared to other orthogonal arrays. Experiments were conducted with each of the coated carbide tool inserts. The $\mathrm{L}_{27}$ orthogonal array used for experimentation and the values of the output parameters obtained through experimentation is shown in Table 2.

\section{Results and discussion}

\subsection{Surface Roughness $\left(R_{a}\right)$}

The measured values of surface roughness $\left(\mathrm{R}_{\mathrm{a}}\right)$ were analyzed using MINITAB15 software. Regression equations obtained for surface roughness for Hyperlox and $\mathrm{HSN}^{2}$ tool inserts are given in Eqs. (2-3).

$$
\begin{aligned}
& \mathrm{R}_{\mathrm{a}}(\text { Hyperlox })=3.15+0.86 \times \mathrm{v}+0.00301 \times \mathrm{d}-123.2 \times \mathrm{f}+7.00 \times \mathrm{v}^{2}+473 \times \mathrm{f}^{2}-0.00428 \\
& \times \mathrm{v} \times \mathrm{d}+25.0 \times \mathrm{v} \times \mathrm{f}+0.0433 \times \mathrm{d} \times \mathrm{f}-0.00250 \times \mathrm{v}^{2} \times \mathrm{d}-20.7 \times \mathrm{v}^{2} \times \mathrm{f}+0.00820 \times \mathrm{v} \times \\
& \mathrm{d} \times \mathrm{f}-78 \times \mathrm{v} \times \mathrm{f}^{2}-0.1713 \times \mathrm{d} \times \mathrm{f}^{2} \\
& \mathrm{R}_{\mathrm{a}}\left(\mathrm{HSN}^{2}\right)=-13.44-2.5 \times \mathrm{v}+0.01790 \times \mathrm{d}+34.1 \times \mathrm{f}-3.20 \times \mathrm{v}^{2}+356 \times \mathrm{f}^{2}+0.00510 \times \\
& \mathrm{v} \times \mathrm{d}+4.6 \times \mathrm{v} \times \mathrm{f}-0.0948 \times \mathrm{d} \times \mathrm{f}+0.00041 \times \mathrm{v}^{2} \times \mathrm{d}+15.1 \times \mathrm{v}^{2} \times \mathrm{f}-0.0147 \times \mathrm{v} \times \mathrm{d} \times \mathrm{f}+ \\
& 43 \times \mathrm{v} \times \mathrm{f}^{2}-0.1341 \times \mathrm{d} \times \mathrm{f}^{2}
\end{aligned}
$$

A low value of the predicted r-square shown in Table 3 indicates that the regression equation obtained can be used only for estimating the $\mathrm{R}_{\mathrm{a}}$ value within the bounds of the input parameters. It cannot be used to predict the value of $\mathrm{R}_{\mathrm{a}}$ outside the bounds of the machining parameters selected for experimentation.

\section{Table 3}

The model summary table for surface roughness $\left(\mathrm{R}_{\mathrm{a}}\right)$

\begin{tabular}{cccc}
\hline Regression model & Tool coating used & r-square & r-square (predicted) \\
\multirow{2}{*}{$\mathrm{R}_{\mathrm{a}}$} & Hyperlox & $98.08 \%$ & $32.24 \%$ \\
& $\mathrm{HSN}^{2}$ & $98.37 \%$ & $18.62 \%$ \\
\hline
\end{tabular}

The main effects plot for surface roughness is shown in Fig. 2. It shows that surface roughness is predominantly influenced by feed (Asiltürk \& Akkuş, 2011). The increase in feed value increases the surface roughness and vice versa (Das et al., 2015; Asiltürk \& Akkuş, 2011; Aslan et al., 2007). The effect of input process parameters on surface roughness is found to be the same in both the tool inserts.

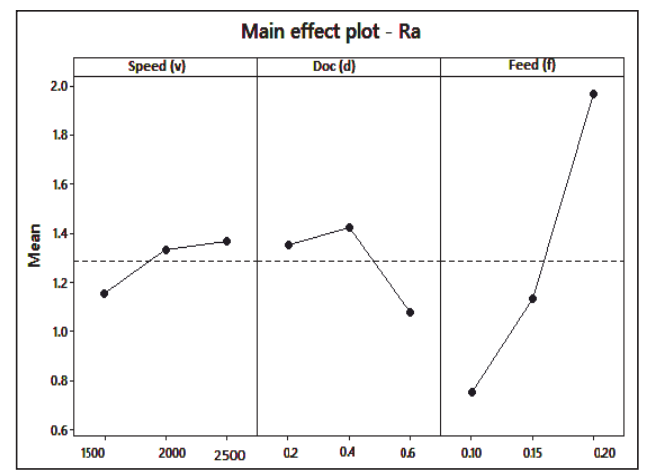

(a)

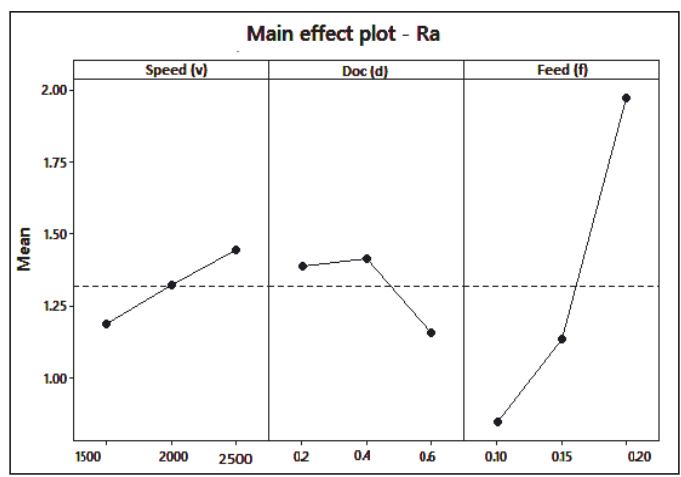

(b)

Fig.2. Main effects plot for surface roughness of (a) Hyperlox tool insert and (b) $\mathrm{HSN}^{2}$ tool insert 
Analysis of variance (ANOVA) was performed with a confidence level of $95 \%$ to find the parameters influencing surface roughness and the result are shown in Table 4. Tool feed rate is the most influencing parameter as seen from the P-value (zero) for both the tool inserts in Table 4. Lower value of the tool feed rate reduces the number of peaks and valleys reducing surface roughness.

\section{Table 4}

ANOVA table showing the significance of input process parameters on surface roughness $\left(R_{a}\right)$ in terms of P-value

\begin{tabular}{|c|c|c|c|c|c|}
\hline Source & Degree of freedom & Sum of Squares & Mean square & F-Value & P-Value \\
\hline \multicolumn{6}{|c|}{ Hyperlox tool insert } \\
\hline $\mathrm{V}$ & 2 & 0.2301 & 0.11505 & 3.10 & 0.067 \\
\hline $\mathrm{f}$ & 2 & 6.9319 & 3.46593 & 93.32 & 0 \\
\hline$d$ & 2 & 0.5998 & 0.29991 & 1.08 & 0.603 \\
\hline Error & 20 & 0.7428 & 0.03714 & & \\
\hline Total & 26 & 8.5045 & & & \\
\hline \multicolumn{6}{|c|}{$\mathrm{HSN}^{2}$ tool insert } \\
\hline $\mathrm{V}$ & 2 & 0.3545 & 0.17727 & 2.04 & 0.156 \\
\hline f & 2 & 6.1203 & 3.06014 & 35.21 & 0 \\
\hline d & 2 & 0.2952 & 0.14760 & 1.70 & 0.208 \\
\hline Error & 20 & 1.7383 & 0.08692 & & \\
\hline Total & 26 & 8.5084 & & & \\
\hline
\end{tabular}

\subsection{Flank Wear Analysis}

Analysis of variance for flank wear was performed for a confidence level of $95 \%$. Regression equation obtained for flank wear of the Hyperlox tool insert is given in Eq. 4 and that of $\mathrm{HSN}^{2}$ is given in Eq. (5).

$$
\begin{aligned}
& \mathrm{V}_{\mathrm{B}}(\text { Hyperlox })=-0.086+0.87 \times \mathrm{v}-0.87 \times \mathrm{f}-1.68 \times \mathrm{v}^{2}-6.3 \times \mathrm{f}^{2}-0.00041 \times \mathrm{v} \times \mathrm{d}+5.18 \times \mathrm{v} \times \mathrm{f}+ \\
& 0.00136 \times \mathrm{d} \times \mathrm{f}+0.000814 \times \mathrm{v}^{2} \times \mathrm{f}-0.00267 \times \mathrm{v} \times \mathrm{d} \times \mathrm{f}-5.9 \times \mathrm{v} \times \mathrm{f}^{2}+0.0029 \times \mathrm{d} \times \mathrm{f}^{2} \\
& \mathrm{~V}_{\mathrm{B}}\left(\mathrm{HSN}^{2}\right) \quad=-0.13+0.93 \times \mathrm{v}+0.000028 \times \mathrm{d}-0.59 \times \mathrm{f}-1.73 \times \mathrm{v}^{2}-6.6 \times \mathrm{f}^{2}-0.00042 \times \mathrm{v} \times \mathrm{d} \\
& +4.81 \times \mathrm{v} \times \mathrm{f}+0.00120 \times \mathrm{d} \times \mathrm{f}+0.000834 \times \mathrm{v}^{2} \times \mathrm{d}+0.95 \times \mathrm{v}^{2} \times \mathrm{f}-0.00271 \times \mathrm{v} \times \mathrm{d} \times \mathrm{f}-4.9 \times \mathrm{v} \times \mathrm{f}^{2} \\
& +0.0029 \times \mathrm{d} \times \mathrm{f}^{2}
\end{aligned}
$$

The r-square value for flank wear is given in Table 5. The lower values of predicted r-square indicate that the regression equation obtained from the experiment cannot be used beyond the limits of bounds of the parameters used in this study.

\section{Table 5}

The model summary table for flank wear $\left(\mathrm{V}_{\mathrm{B}}\right)$

\begin{tabular}{cccc}
\hline Regression model & Tool coating used & r-square & r-square (predicted) \\
\hline \multirow{2}{*}{$V_{\mathrm{B}}$} & Hyperlox & $80.96 \%$ & $20.88 \%$ \\
& HSN $^{2}$ & $79.73 \%$ & $23.4 \%$ \\
\hline
\end{tabular}

Fig. 3a and Fig. $3 \mathrm{~b}$ shows that the flank wear increases in inverse proportion with spindle speed (Aslan et al., 2007) for both the tools. This is because when the spindle speed is reduced, cutting force is also reduced favoring the formation of serrated chips. The serrated chips in turn increases the flank wear.

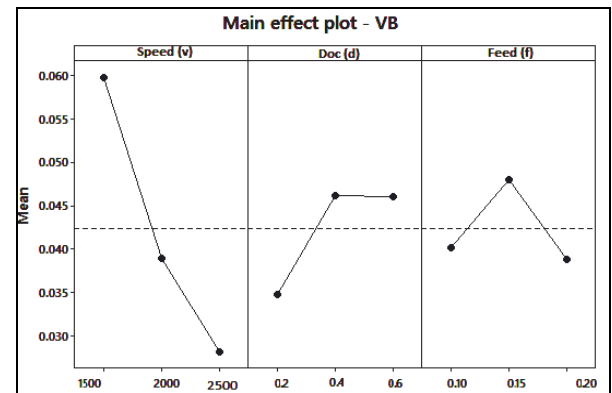

(a)

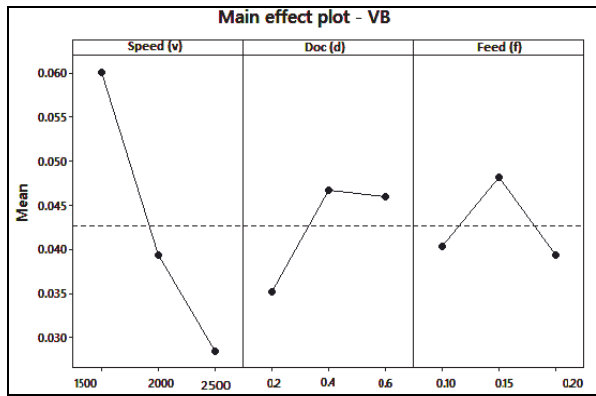

(b)

Fig. 3. Main effects plot for flank wear (a) Hyperlox tool insert and (b) $\mathrm{HSN}^{2}$ tool insert 
Table 6

ANOVA table showing the significance of input process parameters on flank wear $V_{B}$

\begin{tabular}{|c|c|c|c|c|c|}
\hline Source & Degrees of freedom & $\begin{array}{l}\text { Sum of } \\
\text { squares }\end{array}$ & Mean square & F-Value & P-Value \\
\hline \multicolumn{6}{|c|}{ Hyperlox tool insert } \\
\hline $\mathrm{v}$ & 2 & 0.004647 & 0.002323 & 3.45 & 0.045 \\
\hline $\mathrm{f}$ & 2 & 0.000442 & 0.000221 & 0.30 & 0.745 \\
\hline $\mathrm{d}$ & 2 & 0.000767 & 0.000383 & 0.52 & 0.603 \\
\hline Error & 20 & 0.014775 & 0.000739 & & \\
\hline Total & 26 & 0.020630 & & & \\
\hline \multicolumn{6}{|c|}{$\mathrm{HSN}^{2}$ tool insert } \\
\hline $\mathrm{v}$ & 2 & 0.000747 & 0.000374 & 3.25 & 0.040 \\
\hline $\mathrm{f}$ & 2 & 0.000422 & 0.000211 & 0.28 & 0.760 \\
\hline d & 2 & 0.004628 & 0.002314 & 0.49 & 0.618 \\
\hline Error & 20 & 0.015178 & 0.000759 & & \\
\hline Total & 26 & 0.020975 & & & \\
\hline
\end{tabular}

The results of analysis of variance (ANOVA) are shown in Table 6. The spindle speed (v) is the most influential input process parameter as evident from the P-value (0.045 and 0.04) given in Table 6 which is below 0.05 .

\subsection{Volumetric Material Removal Rate Analysis}

As the volumetric material removal rate was calculated using the conventional formula given in Eq.1, it is high when all the parameters are at their highest value as shown in Fig. 4. Regression equation obtained for MRR when using Hyperlox and $\mathrm{HSN}^{2}$ tool inserts for machining are given in Eq. (6).

$$
\operatorname{MRR}\left(\text { Hyperlox and } \mathrm{HSN}^{2}\right)=-28860+28036 \times v+7.42 \times d+98964 \times f
$$

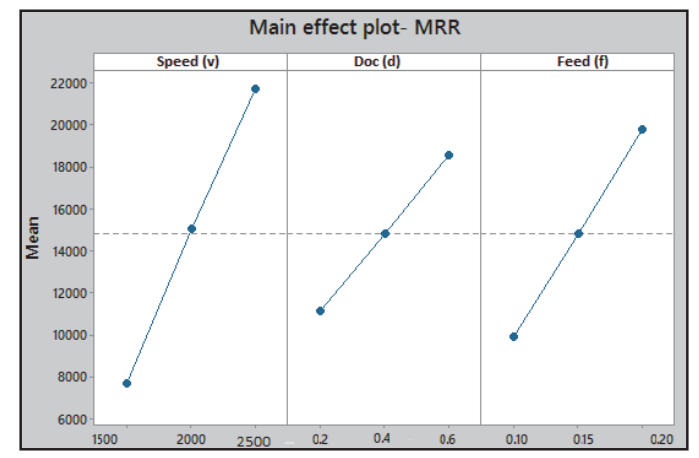

Fig. 4. Main effects plot for volumetric material removal rate when machining the work material with the Hyperlox and $\mathrm{HSN}^{2}$ tool inserts.

Table 7

ANOVA table showing the significance of input process parameters on the volumetric material removal rate (MRR)

\begin{tabular}{|c|c|c|c|c|c|}
\hline Source & Degree of freedom & Sum of Squares & Mean square & F-Value & P-Value \\
\hline \multicolumn{6}{|c|}{ Hyperlox tool insert } \\
\hline $\mathrm{v}$ & 2 & 884999388 & 442499694 & 71.61 & 0 \\
\hline $\mathrm{f}$ & 2 & 247774133 & 123887067 & 20.05 & 0 \\
\hline $\mathrm{d}$ & 2 & 440725685 & 220362843 & 35.66 & 0 \\
\hline Error & 20 & 123588588 & 6179429 & & \\
\hline Total & 26 & 1697087795 & & & \\
\hline \multicolumn{6}{|c|}{$\mathrm{HSN}^{2}$ tool insert } \\
\hline $\mathrm{V}$ & 2 & 884999388 & 442499694 & 71.61 & 0 \\
\hline $\mathrm{f}$ & 2 & 247774133 & 123887067 & 20.05 & 0 \\
\hline $\mathrm{d}$ & 2 & 440725685 & 220362843 & 35.66 & 0 \\
\hline Error & 20 & 123588588 & 6179429 & & \\
\hline Total & 26 & 1697087795 & & & \\
\hline
\end{tabular}


As the conventional formula is used to calculate the theoretical volumetric MRR, the r-square values obtained for the regression equation is equal to 100 percent for both the tool inserts and the regression equation for MRR remains the same for both the tool inserts. The results of analysis of variance (ANOVA) are shown in Table 7. Since the P-value of all the parameters are equal to zero, all the three parameters equally influence the MRR.

\section{Multi-objective optimization using genetic algorithm}

Genetic Algorithm (GA) is a directed search, global optimization algorithm that provides the initial solution with a set of initial population. The initial population is taken from the bounds of input parameters and the initial solution of $R_{a}, V_{B}$ and $M R R$ are found. With this initial solution, the algorithm will then iterate to find the second generation and it will continue the iteration till the stopping criterion is reached. The initial population may be a set of randomly generated numbers or may be a set of probable solutions in case where much knowledge is already gained about the process. In this work the initial population chosen is within the limits of bounds of parameters. This will reduce the computation time for the optimization problem (Pham et al., 2000). Genetic algorithm optimizes the given problem using operators like selection, crossover, mutation and inversion. In this work multi-objective optimization with GA is done using the multi-objective optimization toolbox of MATLAB software.

The various functions used in the multi-objective optimization toolbox are shown in Table 8. A function is created to code the regression equation of surface roughness, tool wear and material removal rate and to combine them to form the multi-objective equation. A code is developed and this function is then saved as $\mathrm{m}$-file and called in the multi-objective optimization tool box for the purpose of optimization.

Table 8

Functions used in Matlab multi-objective optimization tool box

\begin{tabular}{|c|c|c|}
\hline Functions & Fed input & Definition \\
\hline Fitness function & @ga_hyperlox & $\begin{array}{l}\text { It is the name of the function created for the purpose of multi-objective } \\
\text { optimization. }\end{array}$ \\
\hline Number of variables & 3 & $\begin{array}{l}\text { It is the total number of parameters under consideration for study or the } \\
\text { number of variables in the function definition }\end{array}$ \\
\hline Bounds & $\begin{array}{c}\text { Lower Bound } \\
{\left[\begin{array}{lll}1500 & 0.25 & 0.1\end{array}\right]} \\
\text { Upper Bound } \\
{\left[\begin{array}{lll}2500 & 0.75 & 0.2\end{array}\right]}\end{array}$ & $\begin{array}{l}\text { These are the values of lower and upper most values of speed, depth of cut } \\
\text { and feed respectively. }\end{array}$ \\
\hline
\end{tabular}

The initial population for each type of the coated tool was changed in every iteration. The stopping criteria obtained by changing the initial population is checked every time. The convergence plot and the stopping criteria of $100 \%$ is achieved for an initial population of 36 for Hyperlox and for an initial population of 32 for $\mathrm{HSN}^{2}$ tool inserts.

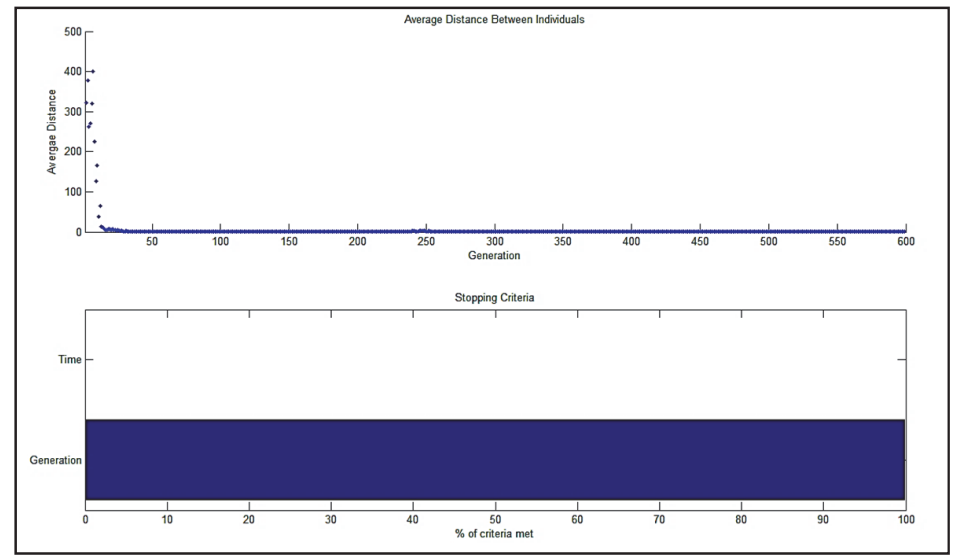

Fig.5. The convergence plot and the percentage of stopping criteria met 
The convergence plot and the percentage of stopping criterion obtained are shown in Fig. 5. GA continue the iteration till the stopping criterion of $100 \%$ is reached. At the end of the iterations the algorithm generates a population of individuals that are optimal. These optimal output parameters differ by a small value because the average distance between the individuals is close to zero. The solution of an optimum combination of input parameters and the corresponding output parameters provided by GA for the two different tool inserts is shown in Table 9 and in Fig. 6. It shows that the Hyperlox tool insert has superior performance than $\mathrm{HSN}^{2}$ tool insert. It is due to the higher hardness of AlTiN of the coating (Bouzakis et al., 2007), that imparts wear resistance. The solution provided by GA was validated through confirmation experiments which showed an average of $85 \%$ conformance with the results.

\section{Table 9}

Optimum combination of input parameters and output parameters obtained using genetic algorithm based multi-objective optimization approach

\begin{tabular}{ccccccc}
\hline \multirow{2}{*}{$\begin{array}{c}\text { Type of tool } \\
\text { coating }\end{array}$} & $\begin{array}{c}\text { Speed } \\
(\mathrm{rpm})\end{array}$ & $\begin{array}{c}\text { Feed } \\
(\mathrm{mm} / \mathrm{rev})\end{array}$ & $\begin{array}{c}\text { Depth of cut } \\
(\mathrm{mm})\end{array}$ & $\begin{array}{c}\text { Surface rough- } \\
\text { ness } \\
\mathrm{R}_{\mathrm{a}}(\mu \mathrm{m})\end{array}$ & $\begin{array}{c}\text { Tool wear } \\
\mathrm{V}_{\mathrm{B}}(\mathrm{mm})\end{array}$ & $\begin{array}{c}\text { MRR } \\
\left(\mathrm{mm}^{3} / \mathrm{min}\right)\end{array}$ \\
\hline Hyperlox $_{\mathrm{HSN}^{2}}$ & 2456.63 & 0.11 & 0.75 & 1.894 & 0.15814 & 29432.86 \\
\hline
\end{tabular}

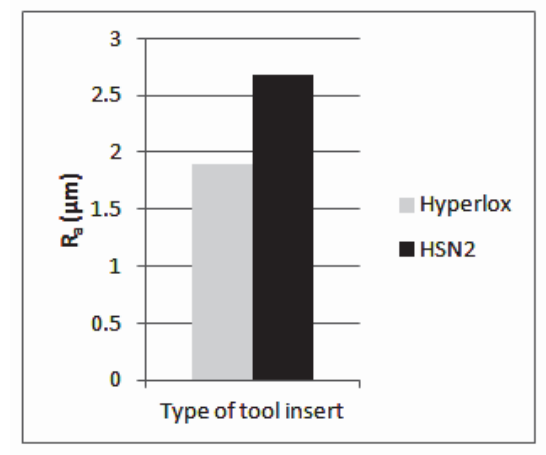

(a)

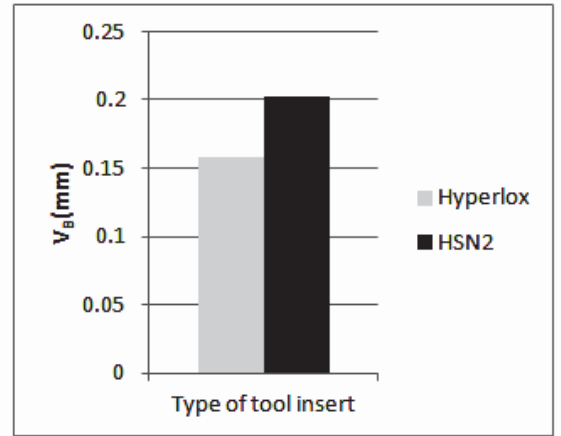

(b)

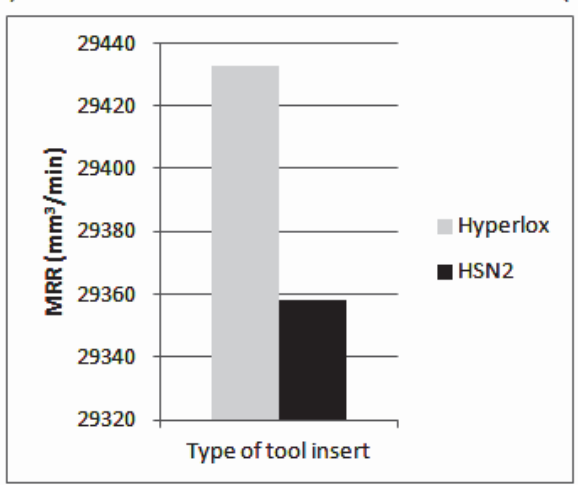

(c)

Fig. 6. Comparison of performance of Hyperlox and $\mathrm{HSN}^{2}$ tool inserts on

(a) Surface roughness $\left(\mathrm{R}_{\mathrm{a}}\right)(\mathrm{b})$ Flank wear $\left(\mathrm{V}_{\mathrm{B}}\right)$ and (c) Volumetric MRR

\section{Conclusion}

Thus, machining of Inconel 600 was successfully carried out and regression equations were obtained for surface roughness $\left(R_{a}\right)$, volumetric $M R R$ and tool wear $\left(V_{B}\right)$. These equations were converted into a multi-objective equation and was solved using genetic algorithm based multi-objective optimization toolbox in MATLAB. An optimum combination of input parameters and the corresponding optimum 
solution for $R_{a}$, MRR and $V_{B}$ were obtained. The performance of both the tools for machining Inconel 600 was compared and the following conclusions are drawn:

(1) Optimum combination of process parameters given by the GA tool box for Hyperlox tool insert is spindle speed $2456.63 \mathrm{rpm}$, tool feed rate $0.11 \mathrm{~mm} / \mathrm{rev}$ and depth of cut $0.75 \mathrm{~mm}$. The optimum combination of process parameters and for $\mathrm{HSN}^{2}$ tool insert is spindle speed $2344.78 \mathrm{rpm}$, tool feed rate $0.1011 \mathrm{~mm} / \mathrm{rev}$ and depth of cut $0.75 \mathrm{~mm}$. The solution given by GA after solving the multi-objective equation shows maximum spindle speed and depth of cut within their bounds as the MRR is to be maximized whereas the tool feed is minimum as the surface roughness $R_{a}$ and tool wear $V_{B}$ are to be minimized.

(2) P-value conveys the weight of evidence against a hypothesis. Higher the value of $\mathrm{P}$, higher is the probability that the hypothesis is wrong. For $95 \%$ confidence level the P-value must not be more than 0.05 (Douglas C. Montgomery, 2003). The results show that the feed rate is statistically significant for surface roughness in both the tool inserts due to the lower value of P. All the input process parameters considered in this study are statistically significant for MRR due to lower values of $\mathrm{P}$ (zero). The input process parameters considered in this study are not statistically significant for tool wear due to high values of P. It is because other factors like tool nose radius, vibration and chatter in the machine tool are not considered as input parameters (Das et al., 2015).

(3) The results of optimization obtained shows that the Hyperlox tool insert is superior in performance than the $\mathrm{HSN}^{2}$ tool insert. The Hyperlox tool insert is capable of yielding $29 \%$ lower value of surface roughness, $22 \%$ lower value of tool wear and $0.2 \%$ higher value of MRR than the $\mathrm{HSN}^{2}$ tool insert.

\section{Acknowledgement}

The authors would like to thank PSG College of Technology, Coimbatore, India, and PSG FANUC Center for Excellence in Robotics, Coimbatore, India, for providing the necessary infrastructure and facilities to complete this work.

\section{References}

Asiltürk, I., \& Akkuş, H. (2011). Determining the effect of cutting parameters on surface roughness in hard turning using the Taguchi method. Measurement, 44(9), 1697-1704.

Aslan, E., Camuşcu, N., \& Birgören, B. (2007). Design optimization of cutting parameters when turning hardened AISI 4140 steel $(63 \mathrm{HRC})$ with $\mathrm{Al}_{2} \mathrm{O}_{3}{ }^{+}$TiCN mixed ceramic tool. Materials \& Design, 28(5), 1618-1622.

Bouzakis, K. D., Michailidis, N., Gerardis, S., Batsiolas, M., Papa, M., Lili, E., \& Cremer, R. (2007). An innovative methodology for the performance evaluation of coated cemented carbide inserts in milling of inconel 718. CIRP Annals-Manufacturing Technology, 56(1), 77-80.

Das, S. R., Dhupal, D., \& Kumar, A. (2015). Experimental investigation into machinability of hardened AISI 4140 steel using TiN coated ceramic tool. Measurement, 62, 108-126.

Douglas C. Mongomery. (2003). Introduction to Statistical Quality Control, John Wiley \& Sons Inc., USA.

Del Prete, A., Primo, T., \& Franchi, R. (2013). Super-nickel orthogonal turning operations optimization. Procedia CIRP, 8, 164-169.

Philip J Ross, (2005). Taguchi Techniques for Quality Engineers, Tata McGraw Hill, New Delhi.

Wu, C. J., \& Hamada, M. S. (2011). Experiments: planning, analysis, and optimization (Vol. 552). John Wiley \& Sons.

Pham,D.T and Karaboga,D. (2000). Intelligent optimization techniques Genetic Algorithms, Tabu search, Simulated Annealing and Neural Networks, Springer, London. 
Samanta, S., \& Chakraborty, S. (2011). Parametric optimization of some non-traditional machining processes using artificial bee colony algorithm. Engineering Applications of Artificial Intelligence, 24(6), 946-957.

Sardinas, R. Q., Santana, M. R., \& Brindis, E. A. (2006). Genetic algorithm-based multi-objective optimization of cutting parameters in turning processes. Engineering Applications of Artificial Intelligence, 19(2), 127-133.

Zhang, H. Y., Lu, Y. H., Ma, M., \& Li, J. (2014). Effect of precipitated carbides on the fretting wear behavior of Inconel 600 alloy. Wear, 315(1-2), 58-67.

Yadav, R. K., Abhishek, K., \& Mahapatra, S. S. (2015). A simulation approach for estimating flank wear and material removal rate in turning of Inconel 718. Simulation Modelling Practice and Theory, 52, $1-14$.

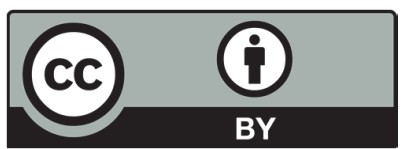

(C) 2018 by the authors; licensee Growing Science, Canada. This is an open access article distributed under the terms and conditions of the Creative Commons Attribution (CCBY) license (http://creativecommons.org/licenses/by/4.0/). 